\title{
Glycemic and lipidic profile in diabetic patients undergoing dialysis
}

\author{
Controle glicêmico e lipídico no paciente diabético em diálise
}

Paulo Cezar Fortes ${ }^{1}$, Jamille Godoy Mendes ${ }^{1}$, Karoline Sesiuk$^{1}$, Letícia Barros Marcondes ${ }^{1}$ Carlos Alberto Mayora Aita' , Miguel Carlos Riella', Roberto Pecoits-Filho'

\begin{abstract}
Objective: The aim of this study is to assess the clinical care pattern and to compare the lipid and glycemic profile in a group of diabetic patients undergoing both hemodialysis (HD) and peritoneal dialysis (PD) and to correlate these data using biomarkers of cardiovascular risk. Subjects and methods: The first phase consisted in performing a survey on demographic data, questions about the medical team and glycemic control. In the second phase, patients were assessed through laboratorial data on their glycemic and lipid profile at a single center for HD and PD. Results: 91 patients was the total population; 70 patients $(77 \%)$ answered the survey; 66 patients $(94 \%)$ considered the nephrologist the physician responsible for caring for their glycemic control. Second phase: 59 patients were assessed, 29 undergoing $\mathrm{HD}$ and 30 undergoing PD. Fifty-seven percent of the patients had $\mathrm{HbA} 1 \mathrm{c}$ above $7 \%$; the level of glycemic markers in patients undergoing peritoneal dialysis was significantly higher than in patients undergoing hemodialysis: $\mathrm{HbA1c}(9.37 \pm 0.5)$ vs. $(7.37 \pm 0.49) \mathrm{p}<$ 0.01 ; fasting glycemia $(170 \pm 15) \mathrm{vs}$. $(126 \pm 15) \mathrm{mg} / \mathrm{dL} p<0.05$. We found a positive correlation between $\mathrm{HbA} 1 \mathrm{c}$ and hyperfibrinogenemia $(r=0.4437, \mathrm{p}<0.0005)$. Conclusions: The data reveal that glycemic control in diabetic patients undergoing renal replacement therapy (RRT) is neglected. Peritoneal dialysis is related to the worst level of glycemic markers, possibly due to the glucose content in the dialysis solution, and higher levels from $\mathrm{HbA} 1 \mathrm{c}$ have a positive correlation with hyperfibrinogenesis in this population. Arq Bras Endocrinol Metab. 2010;54(9):793-800
\end{abstract}

\section{Keywords}

Glycemic control; insulin resistance; chronic kidney disease; peritoneal dialysis; inflammation

\section{RESUMO}

Objetivo: Avaliar as características dos cuidados clínicos dos pacientes em diálise, comparar o controle glicêmico e lipídico entre os pacientes diabéticos em hemodiálise (HD) e em diálise peritoneal (DP) e correlacionar os dados laboratoriais com biomarcadores de risco cardiovascular. Sujeitos e métodos: A primeira etapa consistiu de um questionário abordando variáveis demográficas, questões sobre a equipe multidisciplinar, incluindo a equipe médica e sobre o controle glicêmico. $\mathrm{Na}$ segunda, os pacientes foram avaliados com exames laboratoriais para controle glicêmico e perfil lipídico numa unidade de HD e DP. Resultados: Dos 91 pacientes avaliados, setenta (77\%) responderam ao questionário. Destes, $66(94 \%)$ consideraram o nefrologista o médico responsável pelo cuidado do seu controle glicêmico. Na segunda etapa, foram avaliados 59 pacientes: 29 em HD e 30 em DP. Cinquenta e sete por cento dos pacientes diabéticos em diálise apresentaram $\mathrm{HbA} 1 \mathrm{c}$ acima de $7 \%$, sendo que aqueles em diálise peritoneal apresentam níveis de marcadores glicêmicos significativamente piores do que os pacientes diabéticos em $\mathrm{HD}, \mathrm{HbA} 1 \mathrm{c}$ : $(9,37 \pm 0,5)$ vs. $(7,37 \pm 0,49) p<0.01$; glicemia de jejum: $(170 \pm 15)$ vs. $(126 \pm 15) \mathrm{mg} / \mathrm{dL}, \mathrm{p}<0.05$. Encontramos uma correlação positiva entre HbA1c e hiperfibrinogenemia $(r=0.4437, p<0.0005)$. Conclusões: Nossos dados permitem inferir que o controle glicêmico da população diabética em terapia renal de substituição (TRS) é negligenciado. A diálise peritoneal está relacionada com piora nos níveis de marcadores glicêmicos, possivelmente em decorrência do conteúdo de glicose das soluções de diálise, e os níveis elevados de HbA1c estão associados com hiperfibrinogenemia nesta população. Arq Bras Endocrinol Metab. 2010;54(9):793-800

Descritores

Controle glicêmico; resistência insulínica; doença renal crônica; diálise peritoneal; inflamação
'Biology and Health Sciences Center, Pontifícia Universidade Católica do Paraná (PUCPR) and Fundação Pró-Renal Brasil, Curitiba, PR, Brazil

Correspondence to: Roberto Pecoits-Filho Centro de Ciências Biológicas e da Saúde

Rua Imaculada Conceição, 1155 80215-901 - Curitiba, PR, Brazil r.pecoits@pucpr.br

Received on Sept/26/2009 Accepted on Oct/21/2010 


\section{INTRODUCTION}

$D$ iabetes mellitus (DM) is currently the pathology most commonly associated with chronic kidney disease (CKD) in many countries. In the United States, it is estimated that 19 million people over 20 years old are diabetic and, out of 19 million, 400 thousand people show signs of CKD (1). In Brazil, diabetic nephropathy is the second cause leading to $\mathrm{CKD}$, responsible for $25 \%$ of the total number of the dyalitic population, according to the latest survey of the Brazilian Nephrology Society $(2,3)$. This leads to a high number of diabetic patients undergoing renal replacement therapy (RRT). These numbers seem to be increasing, what makes this issue a relevant public health problem. This fact has serious implications for this population, especially because of the higher morbidity and lower survival rate when compared to non-diabetic patients undergoing dialysis (2).

Appropriate glycemic control is essential to prevent microvascular and macrovascular disease as well as to reduce cardiovascular events in diabetic patients without CKD (4-7). Patients undergoing RRT present a high mortality rate due to cardiovascular causes and treatment recommendations not yet clearly defined. In addition, the difference between RRT techniques (hemodialysis and peritoneal dialysis) may contribute to the patients' lack of metabolic control. For example, the glucose dose used as an ultrafiltration generator agent in peritoneal dialysis represents a risk factor for lack of glycemic control (8). Only recently, guidelines provided by nephrology societies have become available to deal with diabetic patients undergoing dialysis. These guidelines offered by K-DOQI (Kidney Disease Outcomes Quality Initiative) are an attempt to reach better glycemic and lipid control in diabetic patients undergoing RRT (9).

Thus, the aim of this study is to identify the clinical care profile of diabetic patients undergoing RRT, to assess and compare glycemic and lipid control among diabetic patients on hemodialysis (HD) and on peritoneal dialysis (PD) sessions, through socio-demographic and laboratory data, as well as to correlate laboratory data with cardiovascular risk biomarkers.

\section{SUBJECTS AND METHODS}

This study was performed at Fundação Pró-renal peritoneal dialysis clinic and at PUCPR Cajuru University
Hospital hemodialysis clinic, both located in Curitiba, Brazil. The criteria for inclusion were: to be older than 18 years old, to have taken part in a dialysis program for over 3 months, to have signed an Informed Consent Form, to have diabetes diagnosis determined by means of revision of the medical record and/or due to the presence of fasting glycemia over $126 \mathrm{mg} / \mathrm{dL}$ in at least two assessments during the last 6 months. The criteria of exclusion were: to have an active infectious disease, to have had blood transfusion three months before sample collection, and refusal to participate in the study. An Informed Consent Form was provided for each patient participating in the study and the study protocol was submitted to PUCPR Research Ethics Committee before being applied (protocol number 770/2005).

The study was developed in two phases. The first phase, involved applying a questionnaire to all diabetic patients undergoing renal substitution therapy. Demographic variables such as age, gender, and questions about the multidisciplinary team including the medical team, have been included. The questionnaire comprehended how long the patient had been undergoing renal substitution therapy, date of diabetes diagnosis, data on glycemic control and data on the medical care given to these patients. Particular attention was given to the medical profession specialties that control diabetes, medication, and to the methods used by the patient for glycemic control.

During the second phase, diabetic patients assessed in the first phase were submitted to blood sample collections which took place from December 2005 to March 2006. The monthly routine of laboratory exams performed on patients undergoing hemodialysis and peritoneal dialysis was collected including hemoglobin, albumin, calcium, phosphorus and parathormone, and blood samples for this study were collected at the same time. Glycemic markers as glycemia were measured by using an automated method glucose-oxidase, glycated hemoglobin was measured by means of high performance liquid chromatography and insulin by means of MEIA-AXSYM, while insulin resistance was calculated through the homeostasis model assessment (HOMA-IR). Serum total cholesterol, HDL-c, LDL-c, and triglycerides were assessed via the automated direct method. Lipid markers were assessed according to the guidelines provided by the American Diabetes Association for lipid control in patients with CKD (9). The following inflammatory activity markers were used: fibrinogen 
was measured through coagulometric testing (Dade Coagulation System) and ultrasensitive C-reactive protein through immunonephelometry. Concerning hemodialysis, blood samples were collected before the session. In relation to peritoneal dialysis, samples were collected together with the samples of the monthly routine exams. On the same date, all peritoneal dialysis patients performed their habitual change of peritoneal dialysis bags. The abdominal circumference was measured without dialysate in those patients. Every patient fasted for eight hours before blood sample collection. The samples were sent to Frishmann Eisengart Laboratory which performed the tests.

Comparison between the groups was performed using Student t-test, ANOVA, Mann Whitney, chi-square or Wilcoxon tests. Correlations were established based either on Pearson's or Spearman's coefficient. Values of $\mathrm{p}$ below 0.05 were considered significant. All the tests were performed by using the JMP for Windows software.

\section{RESULTS}

We evaluated 127 patients undergoing regular hemodyalitic treatment and 48 patients (37\%) fulfilled inclusion criteria and were invited to participate in the study. At the peritoneal dialysis clinic, 124 patients were screened and 43 (35\%) were approached to participate.

The first phase 70 patients finished the evaluation, 35 patients undergoing $\mathrm{HD}$ and 35 undergoing PD. In $\mathrm{PD}, 26(75 \%)$ patients were part of a program of continuous ambulatory peritoneal dialysis and $9(25 \%)$ were undergoing automated peritoneal dialysis. Reasons for not including patients encompass difficulty in contac- ting patients (particularly PD patients), refusal to participate or inability to answer because of clinical events at the moment of the inclusion (Figure 1).

The mean age of patients was $62 \pm 9$ years; $56 \%$ were male. Four patients had DM type 1 in peritoneal dialysis and 2 patients with DM type 1 in HD. Follow-up treatment by an endocrinologist was provided to 4 (6\%) patients only; 3 patients in PD and 1 patient in $\mathrm{HD}$; the other patients considered the nephrologist to be the responsible care professional for the control of their diabetes. Twelve patients (34\%) undergoing PD performed self-monitored blood glucose once a month and $12(34 \%)$ more than twice a week, while 16 patients $(46 \%)$ in HD performed self-monitored blood glucose once or twice a week and 19 patients $(54 \%)$ undergoing HD more than twice a week. Sixty $(86 \%)$ patients were not familiar with the glycated hemoglobin (HbAlc) test and only $4(6 \%)$ patients took the test at least once every three months, 3 in PD and only $\mathrm{l}$ in HD. Insulin was used by $35(50 \%)$ patients: 28 in PD and 7 in $\mathrm{HD}$, and the others did not have any pharmacological control. The mean regular daily insulin dose taken by patients was $4 \pm 1$ UI and the dose of NPH insulin was $18 \pm 14$ UI. No patient used oral blood-glucose lowering agents.

The second phase fifty-nine patients out of the 70 who agreed to participate in the study were submitted to blood sample collections for laboratory evaluation (29 in HD and 30 in PD). Eleven patients did not collect the samples because they did not have a regular collection of tests at the unit where they received dialysis due to access difficulties, especially in $\mathrm{PD}$, and due to the fact that they did not have a favorable clinical condition during the collection period.

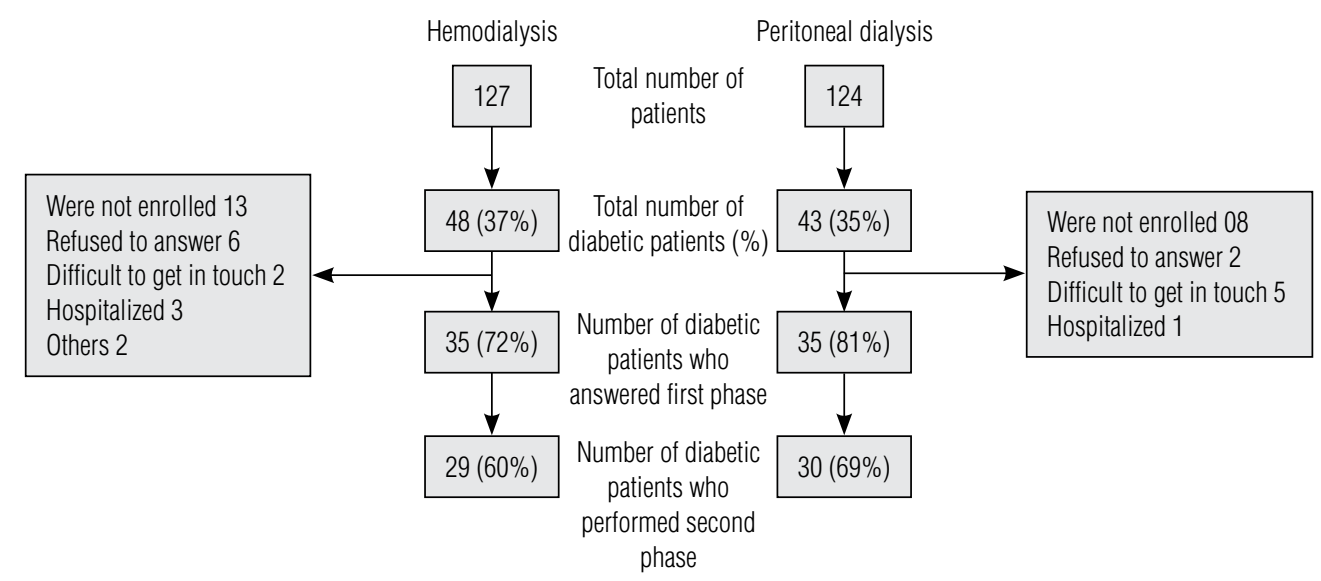

Figure 1. Enrollment and follow-up of study participants. 
The population assessed represents a typical population of diabetic patients undergoing renal replacement therapy in Brazil. Mean age was 61 years, $49 \%$ were women under dyalitic treatment for an average of 30 months, the average time of diagnosis of diabetes was 15 years. Diabetic patients undergoing PD also presented anthropometric markers significantly higher than patients undergoing HD. Table 1 shows the general characteristics of the patients.

Inflammatory activity evaluated by fibrinogen showed a significant increase of fibrinogen levels in patients undergoing peritoneal dialysis when compared to patients undergoing hemodialysis. CRP (C-reactive protein) did not show significant difference between the groups.
Table 2 compares the lipid and glycemic profile of the diabetic patients undergoing dialysis, according to the type of RRT. Glucose control parameters, except for fructosamine, were worse in patients undergoing PD. Thirty-four patients (57\%) presented levels of glycated hemoglobin higher than 7\%, 22 patients $(73 \%)$ of the patients undergoing PD versus 12 patients (41\%) in HD a statistically significant difference between PD and HD. Even though there was no statistically significant difference between the groups, HOMA index tended to be higher in the PD group. There was no significant difference in lipid profile between patients on PD and HD treatments, even when they were dichotomized according to K-DOQI directions (9).

Table 1. General characteristics of diabetic patients undergoing peritoneal dialysis and hemodialysis

\begin{tabular}{|c|c|c|c|c|}
\hline Characteristics & $\begin{array}{c}\text { All patients } \\
(\mathrm{n}=59)\end{array}$ & $\begin{array}{c}\text { DP } \\
(n=30)\end{array}$ & $\begin{array}{c}\text { HD } \\
(n=29)\end{array}$ & $\mathbf{p}^{*}$ \\
\hline Age (years) & $61 \pm 1.3$ & $62 \pm 1.8$ & $61 \pm 1.9$ & n.s \\
\hline Gender $(\mathrm{M} / \mathrm{F})$ & $29 / 30$ & $14 / 16$ & $15 / 15$ & n.s \\
\hline Time undergoing dialysis (months) & $30 \pm 2$ & $30 \pm 2$ & $30 \pm 3$ & n.s \\
\hline Length of time of diabetes (years) & $16 \pm 1$ & $16 \pm 1$ & $14 \pm 2$ & n.s \\
\hline WC (cm) & $102 \pm 2$ & $102 \pm 2$ & $93 \pm 2$ & $<0.05$ \\
\hline $\mathrm{BMI}\left(\mathrm{kg} / \mathrm{m}^{2}\right)$ & $28 \pm 0.9$ & $28 \pm 0.9$ & $25 \pm 0.8$ & $<0.01$ \\
\hline KtV & & $1.98 \pm 0.76$ & $1.2 \pm 0.2$ & - \\
\hline Hemoglobin $(\mathrm{g} / \mathrm{dL})$ & $11.7 \pm 0.2$ & $12.3 \pm 0.27$ & $11.2 \pm 0.27$ & $<0.01$ \\
\hline Albumin (mg/dL) & $3.6 \pm 0.06$ & $3.51 \pm 0.08$ & $3.72 \pm 0.10$ & n.s \\
\hline Calcium (mg/dL) & $9.02 \pm 0.13$ & $8.95 \pm 0.13$ & $9.10 \pm 0.13$ & n.s \\
\hline Phosphorus (mg/dL) & $4.86 \pm 0.20$ & $4.32 \pm 0.20$ & $5.41 \pm 0.21$ & $<0.0005$ \\
\hline Product Ca XP & $44 \pm 2$ & $38.8 \pm 2.23$ & $49.6 \pm 2.27$ & $<0.005$ \\
\hline PTHi (pg/mL) & $180 \pm 55$ & $139 \pm 41$ & $232 \pm 46$ & n.s \\
\hline $\mathrm{CRP}(\mathrm{mg} / \mathrm{dL})$ & $0.59(0.07-8.87)$ & $0.45(0.07-8.87)$ & $0.38(0.07-8.87)$ & n.s \\
\hline Fibrinogen (mg/dL) & $520 \pm 177$ & $613 \pm 27$ & $424 \pm 28$ & $<0.0001$ \\
\hline
\end{tabular}

BMI: body mass index; WC: waist circumference; CRP: C-reactive protein; PTHi: intact parathyroid hormone; n.s: not significant.

${ }^{*}$ Comparison between $\mathrm{HD}$ and $\mathrm{PD}$.

Table 2. Differences in glycemic and lipidic control according to the type of dialysis

\begin{tabular}{|c|c|c|c|c|}
\hline & Total & $\mathrm{DP}(n=30)$ & $H D(n=29)$ & $\mathbf{p}^{\star}$ \\
\hline Fasting glycemia (mg/dL) & $148 \pm 7$ & $170 \pm 15$ & $126 \pm 15$ & $<0.05$ \\
\hline Frutosamine $(\mu \mathrm{mol} / \mathrm{L})$ & $396 \pm 9$ & $397 \pm 16$ & $394 \pm 16$ & n.s \\
\hline HbA1c (\%) & $8.35 \pm 0.2$ & $9.37 \pm 0.5$ & $7.37 \pm 0.49$ & $<0.01$ \\
\hline $\mathrm{HbA} 1 \mathrm{c}>7 \%$ & $34(57 \%)$ & $22(73 \%)$ & $12(41 \%)$ & $<0.005$ \\
\hline HOMA index & $6.43 \pm 1.06$ & $8.4 \pm 1.48$ & $4.5 \pm 1.46$ & 0.0694 \\
\hline Total cholesterol (mg/dL) & $187 \pm 52$ & $181 \pm 9$ & $160 \pm 9$ & n.s \\
\hline $\mathrm{HDL}(\mathrm{mg} / \mathrm{dL})$ & $46 \pm 1.5$ & $46 \pm 1.9$ & $46 \pm 1.9$ & n.s \\
\hline LDL (mg/dL) & $98 \pm 7$ & $98 \pm 7$ & $83 \pm 7$ & n.s \\
\hline Tryglicerides (mg/dL) & $173 \pm 18$ & $181 \pm 22$ & $164 \pm 23$ & n.s \\
\hline
\end{tabular}

HDA1c: glycated hemoglobin; HOMA: homeostasis model assessment; HDL: high-density lipoprotein; LDL: Low density lipoprotein.

* Comparison between $\mathrm{HD}$ and PD. 
When the analysis involving glycemic control markers and inflammatory activity markers was made, we observed a very strong correlation among the glycemic control markers, between glycemia and frutosamine $(\mathrm{r}=0.49, \mathrm{p}<0.0001)$, between frutosamine and HbAlc $(\mathrm{r}=0.67, \mathrm{p}<0.0001)$, and also between HbAlc and glycemia $(r=0.73, \mathrm{p}<0.0001)$. There was a very strong and significant association between the HOMA index (an insulin resistance marker) and HbAlc $(\mathrm{r}=0.4 \mathrm{l}, \mathrm{p}<0.0016)$. We have also noticed a strong correlation between HbAlc and hyperfibrinogenemia $(\mathrm{r}=0.44, \mathrm{p}<0.0005)$, glycemia and hyperfibrinogenemia $(r=0.40, p<0.0017)$, which suggest a correlation between poor glycemic control and the inflammatory phenomenon in this population (Figure 2).

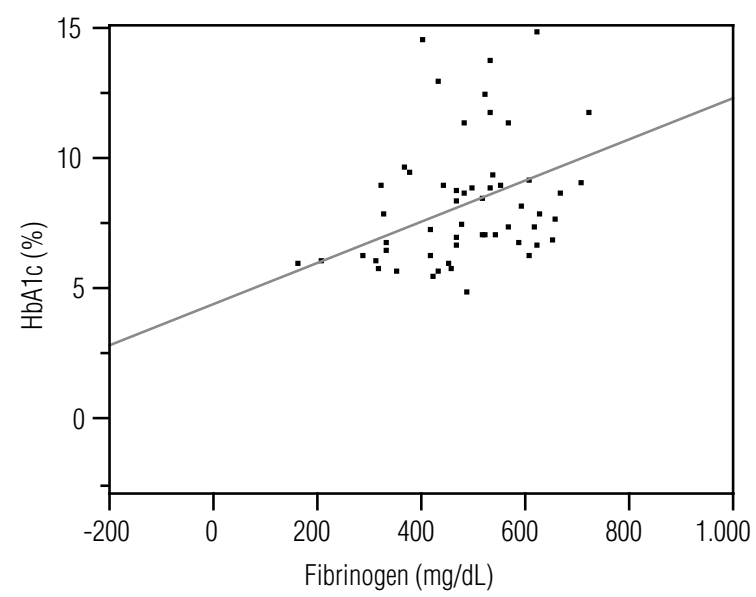

The graph shows a positive correlation between HbA1c and fibrinogenemia suggesting that poor glycemic control is associated with higher levels of a marker of systemic inflammation.

Figure 2. Correlation between $\mathrm{HbA1c}$ and fibrinogen.

\section{DISCUSSION}

Diabetic nephropathy is the second cause leading to CKD in Brazil and glycemic control is an important element to predict the survival rate for Type 2 diabetic patients, both in pre-dialysis (10) and after beginning renal replacement therapy (11-14). In addition, glycemic control is essential for reducing the risk of vascular complications and for improving the quality of life of these patients (15-17). Our study has identified the nephrologist as the most frequent professional responsible for performing glycemic control in diabetic patients undergoing dialysis. Inadequacy concerning glycemic control was also demonstrated, especially in diabetic patients undergoing peritoneal dialysis. Finally, we found there was positive association between glycemic control markers and inflammatory activity markers, which reveals synergy in the development of cardiovascular risk in these patients.

Most diabetic patients undergoing renal replacement therapy consider the nephrologist as the doctor in charge of their glycemic control. Patients had known about their diagnosis for an average time of 15 years before beginning RST and, despite that, most of them showed a significant lack of knowledge of diabetes control markers. This is due to the fact that patients are submitted to poor glycemic control before RRT, and that becomes noticeable in their lack of knowledge of the problem of chronic nephropathy in the initial stages of diabetes $(18,19)$. Therefore, diabetic patients must improve their glycemic control in pre-dialysis as well as after beginning RRT, and that could be achieved by means of educational programs during the different stages of the natural history of the disease and the mandatory participation of endocrinologists in these settings.

Our data have revealed that diabetic patients undergoing dialysis have very poor glycemic control as it has been demonstrated by the high levels of glycated hemoglobin detected; this might be due to the fact that most patients undergoing RRT are unaware of the meaning of this test. In Brazil, this result is compatible with findings regarding the general population, based on the National Study of Diabetes Epidemiology which involved 6,701 patients. Glycemic control was considered inadequate for $75 \%$ of the patients (19). Our study reveals results that are similar to those presented by an American study involving 23,504 diabetic patients undergoing hemodialysis. The American study showed a percentage of patients with $\mathrm{HbAlc}$ values above 7 , equivalent to $35 \%$, versus $41 \%$ from our study (20) that means reasonable control in patients undergoing hemodialysis. Another factor that contributes to this high percentage of patients above the target range is the fact that Brazil does not include HbAlc as a required test in patients undergoing RRT (2l). Despite the fact that K-DOQI guidelines recommend keeping glycated hemoglobin below $7 \%$ in diabetic patients undergoing dialysis (9), this recommendation is not based on clinical trials for the population undergoing RRT, and the target range might be challenged due to the lack of nationwide studies related to this issue, making way for an individualized approach for these patients $(22,23)$.

Moreover, we observed that diabetic patients undergoing peritoneal dialysis show higher levels of 
HbAlc than diabetic patients undergoing hemodialysis. A number of reasons might explain this fact; among these reasons we mention a greater exposition to glucose from the dialysate liquid and also the fact that there might be an obliquity concerning the selection of diabetic patients undergoing peritoneal dialysis (24). Frequently this population is guided towards peritoneal dialysis due to comorbidities such as: when the patients do not have vascular access, associated cardiopathy or more serious microcirculation problems such as retinopathy, for instance, and that might contribute to a worse glycemic control of this population.

We have found a high level of correlation among all the glycemic control markers. However, this fact is not the best way to assess the influence of uremy and the reduction of eritrocitary half-life and its interference upon glycemic control parameters in this population. Nevertheless, Ansari and cols. have demonstrated that glycated hemoglobin might be used as a standard for the assessment of these patients (4), and other studies have associated an increase in hemoglobin to an increase in mortality of diabetic patients as well as in non-diabetic patients undergoing dialysis (25). Recently, the interest in glycated albumin as an alternative for the assessment of glycemic control of these patients has risen (26); however, further studies are necessary for the assessment of the real benefit of replacing a traditional marker, based on greater knowledge in the laic and medical areas.

Our study did not demonstrate significant difference concerning lipid disturbance among the groups; this might be related to the higher control level of the use of medication by patients undergoing peritoneal dialysis, which was not the focus of our study. Perhaps this might be connected to the fact that the treatment of lipid disturbance in diabetic patients undergoing dialysis is controversial, considering that, apart from studies showing that the treatment with atorvastatin does not offer any benefit and it might even increase the occurrence of cardiovascular events in this population (27), patients are also exposed to phenomena connected to reverse epidemiology which demonstrates that factors related to traditional risk such as obesity, hiperlipidemia and hypertension could be protective factors and not bad prognosis for this population (28). The AURORA study has demonstrated that rosuvastatin decreases the LDL of patients undergoing dialysis without affecting cardiovascular mortality $(29,30)$.
A possible explanation would be that the benefits of the decrease of a well established marker such as LDL are not automatically transferred from the general population to the diabetic population undergoing dialysis, considering that the latter might have a spectrum of cardiac disease quite different (31). In this way, SHARP study, currently being developed, based on a sample of 9,000 patients, might bring new evidence to clarify this issue (32).

Resistance to insulin, assessed through HOMA index, is a marker validated in patients who do not have kidney disease and it has been associated to an increase in mortality risk in CKD patients undergoing dialysis $(33,34)$. Our study has demonstrated that there is a tendency of increase in the resistance to insulin in diabetic patients undergoing peritoneal dialysis, what might contribute to the development of cardiovascular disease in these patients (35). Medication to reduce resistance to insulin, especially glitazones, might reduce the need for insulin and also the mortality rate in patients undergoing dialysis; however, these findings must be confirmed and based on clinical trials related to this issue. Concerning glitazones, specifically, retention of fluid is a significant complication for this population $(36,37)$.

The presence of inflammatory markers in patients with CKD is associated with an increase of cardiovascular risk as well as the appearance of a new potential intervention target (38). On the other hand, the association of inflammatory markers (fibrinogenesis) and glycemic control markers $(\mathrm{HbAlc})$ supports the hypothesis that there is a correlation between these phenomena concerning the increase of cardiovascular risk in diabetic patients (39).

Among the challenges of renal substitution therapy, it is worth mentioning the challenge of reaching appropriate glycemic control, especially in patients undergoing peritoneal dialysis. Among the strategies suggested, we propose the implementation of educational programs, and an increase in the use of insulin and its analogous elements in relation to these patients. Fluids for dialysis without glucose in their composition are an alternative for reducing the patient's exposition. In order to replace glucose, these solutions should contain amino acid or icodextrin $(40,41)$ to reduce the dose of glucose in the prescription for dialysis.

In conclusion, the lack of studies focusing on the glycemic control of diabetic patients undergoing dialysis points to the need for greater efforts from the medical community to generate substrate for behavioral 
changes based on clinical evidence, aiming at decreasing morbidity and mortality in this group of patients. There is the urgent need to implement and standardize educational programs on diabetes for diabetic patients undergoing dialysis as well as new strategies for glycemic control, especially for patients undergoing peritoneal dialysis who are at a greater risk due to poor glycemic control, as it has been shown in this study.

Acknowledgement: We would like to thank Fundação Pró-renal, which supports and develops research and study on kidney disease, our colleagues from CAPD, Sirlene Maganhotto Sautier, Maraceli Nicolini, Roseana Fuerbringer and Cleide Salvador Machado, from Cajuru Hospital Hemodialysis Center, Valquíria Dourado, Ana Paula Modesto, Maria Angila Lopes, Giovana Paz, and also our colleagues from PUCPR Health Sciences laboratory, Andrea Sthinghen, Paulo Aveles, Aline Hauser, and Marília Werneck.

Disclosure: no potential conflict of interest relevant to this article was reported.

\section{REFERENCES}

1. Ritz E. Managing anaemia and diabetes: a future challenge for nephrologists. Nephrol Dial Transplant. 2005;20 Suppl 6:vi21-5.

2. Peres LA, Matsuo T, Delfino VD, Peres CP, Netto JH, Ann HK, et al. [Increase in prevalence of diabetes mellitus as a cause of dialytic end-stage renal disease: analysis of 20 years in the west region of Parana]. Arq Bras Endocrinol Metabol. 2007;51(1):111-5.

3. CENSO 2006 [database on the Internet]. Sociedade Brasileira de Nefrologia. 2006 [cited 27 march 2007].

4. Ansari A, Thomas S, Goldsmith D. Assessing glycemic control in patients with diabetes and end-stage renal failure. Am J Kidney Dis. 2003;41(3):523-31.

5. The effect of intensive treatment of diabetes on the development and progression of long-term complications in insulin-dependent diabetes mellitus. The Diabetes Control and Complications Trial Research Group. N Engl J Med. 1993;329(14):977-86.

6. Intensive blood-glucose control with sulphonylureas or insulin compared with conventional treatment and risk of complications in patients with type 2 diabetes (UKPDS 33). UK Prospective Diabetes Study (UKPDS) Group. Lancet. 1998;352(9131):837-53.

7. Nathan DM, Cleary PA, Backlund JY, Genuth SM, Lachin JM, Orchard TJ, et al. Intensive diabetes treatment and cardiovascular disease in patients with type 1 diabetes. $N$ Engl $J$ Med. 2005;353(25):2643-53.

8. SitterT, Sauter M. Impact of glucose in peritoneal dialysis: saint or sinner? Perit Dial Int. 2005;25(5):415-25.

9. KDOQI Clinical Practice Guidelines and Clinical Practice Recommendations for Diabetes and Chronic Kidney Disease. Am J Kidney Dis. 2007;49(2 Suppl 2):S12-154.

10. Wu MS, Yu CC, Wu CH, Haung JY, Leu ML, Huang CC. Pre-dialysis glycemic control is an independent predictor of mortality in type II diabetic patients on continuous ambulatory peritoneal dialysis. Perit Dial Int. 1999;19 Suppl 2:S179-83.

11. Ishimura E, Okuno S, Kono K, Fujino-Kato Y, Maeno Y, Kagitani $S$, et al. Glycemic control and survival of diabetic hemodialysis patients--importance of lower hemoglobin A1C levels. Diabetes Res Clin Pract. 2009;83(3):320-6.
12. Tzamaloukas AH, Murata GH, Zager PG, Eisenberg B, Avasthi PS. The relationship between glycemic control and morbidity and mortality for diabetics on dialysis. Asaio J. 1993;39(4):880-5.

13. Morioka T, Emoto M, Tabata T, Shoji T, Tahara H, Kishimoto $H$, et al. Glycemic control is a predictor of survival for diabetic patients on hemodialysis. Diabetes Care. 2001;24(5):909-13.

14. Kalantar-Zadeh K, Kopple JD, Regidor DL, Jing J, Shinaberger CS, Aronovitz J, et al. A1C and survival in maintenance hemodialysis patients. Diabetes Care. 2007;30(5):1049-55.

15. McMurray SD, Johnson G, Davis S, McDougall K. Diabetes education and care management significantly improve patient outcomes in the dialysis unit. Am J Kidney Dis. 2002;40(3):566-75.

16. Williams ME, Lacson Jr E, Teng M, Hakim RM, Lazarus JM. Extremes of glycemic control $(\mathrm{HbA1c})$ increase hospitalization risk in diabetic hemodialysis patients in the USA. Am J Nephrol. 2009;29(1):54-61.

17. Dronovalli S, Burney BO, Bakris GL. Glycemic control and cardiovascular disease in chronic kidney disease. Curr Diab Rep. 2009;9(3):243-8.

18. Obrador GT, Pereira BJ, Kausz AT. Chronic kidney disease in the United States: an underrecognized problem. Semin Nephrol. 2002;22(6):441-8.

19. Moreira Jr ED, Mendes AB, Chacra AR. Avaliação do grau de controle glicêmico nos diabéticos no Brasil: resultados do estudo nacional da epidemiologia do diabetes. Arq Bras Endocrinol Metabol. 2007;51(7):S459.

20. Williams ME, Lacson Jr E, Teng M, Ofsthun N, Lazarus JM. Hemodialyzed type I and type II diabetic patients in the US: characteristics, glycemic control, and survival. Kidney Int. 2006;70(8):1503-9.

21. Ministério da Saúde, Secretaria de Assistência à Saúde, Portaria número 38, de 3 de março de 1994.

22. Halevy $D$, Vemireddy $M$. Is a target hemoglobin A1c below $7 \%$ safe in dialysis patients? Am J Kidney Dis. 2007;50(1):166; author reply -7 .

23. Kovesdy $\mathrm{CP}$, Sharma $\mathrm{K}$, Kalantar-Zadeh K. Glycemic control in diabetic CKD patients: where do we stand? Am J Kidney Dis. 2008;52(4):766-77.

24. Grodstein GP, Blumenkrantz MJ, Kopple JD, Moran JK, Coburn JW. Glucose absorption during continuous ambulatory peritoneal dialysis. Kidney Int. 1981;19(4):564-7.

25. Menon V, Greene T, Pereira AA, Wang X, Beck GJ, Kusek JW, et al. Glycosylated hemoglobin and mortality in patients with nondiabetic chronic kidney disease. J Am Soc Nephrol. 2005;16(11):3411-7.

26. Inaba $M$, Okuno $S$, Kumeda $Y$, Yamada $S$, Imanishi $Y$, Tabata $T$, et al. Glycated albumin is a better glycemic indicator than glycated hemoglobin values in hemodialysis patients with diabetes: effect of anemia and erythropoietin injection. J Am Soc Nephrol. 2007;18(3):896-903.

27. Wanner C, Krane V, Marz W, Olschewski M, Mann JF, Ruf G, et al. Atorvastatin in patients with type 2 diabetes mellitus undergoing hemodialysis. N Engl J Med. 2005;353(3):238-48.

28. Kalantar-Zadeh K, Block G, Humphreys MH, Kopple JD. Reverse epidemiology of cardiovascular risk factors in maintenance dialysis patients. Kidney Int. 2003;63(3):793-808.

29. Fellstrom B, Holdaas $H$, Jardine AG, Svensson MK, Gottlow M, Schmieder RE, et al. Cardiovascular disease in patients with renal disease: the role of statins. Curr Med Res Opin. 2009;25(1):271-85.

30. Fellstrom BC, Jardine AG, Schmieder RE, Holdaas H, Bannister K, Beutler J, et al. Rosuvastatin and cardiovascular events in patients undergoing hemodialysis. N Engl J Med. 2009;360(14):1395-407.

31. Strippoli GF, Craig JC. Sunset for statins after AURORA? N Engl J Med. 2009;360(14):1455-7.

32. Baigent C, Landry M. Study of Heart and Renal Protection (SHARP). Kidney Int Suppl. 2003;(84):S207-10. 
33. Shoji T, Emoto MYN. HOMA index to assess insulin resistance in renal failure patients. Nephron. 2001;89(3):348-9.

34. Shinohara K, Shoji T, Emoto M, Tahara H, Koyama H, Ishimura E, et al. Insulin resistance as an independent predictor of cardiovascular mortality in patients with end-stage renal disease. J Am Soc Nephrol. 2002;13(7):1894-900.

35. Fortes PC, de Moraes TP, Mendes JG, Stinghen AE, Ribeiro SC, Pecoits-Filho R. Insulin resistance and glucose homeostasis in peritoneal dialysis. Perit Dial Int. 2009;29 Suppl 2:S145-8.

36. Wong TY, Szeto CC, Chow KM, Leung CB, Lam CW, Li PK. Rosiglitazone reduces insulin requirement and $\mathrm{C}$-reactive protein levels in type 2 diabetic patients receiving peritoneal dialysis. Am J Kidney Dis. 2005;46(4):713-9.

37. Schneider CA, Ferrannini E, Defronzo R, Schernthaner G, Yates $J$, Erdmann E. Effect of pioglitazone on cardiovascular outco- me in diabetes and chronic kidney disease. J Am Soc Nephrol. 2008;19(1):182-7.

38. Pecoits-Filho R, Stenvinkel P, Wang AY, Heimburger O, Lindholm B. Chronic inflammation in peritoneal dialysis: the search for the holy grail? Perit Dial Int. 2004;24(4):327-39.

39. Wellen KE, Hotamisligil GS. Inflammation, stress, and diabetes. J Clin Invest. 2005;115(5):1111-9.

40. Babazono $T$, Nakamoto $H$, Kasai K, Kuriyama $S$, Sugimoto $T$, Nakayama M, et al. Effects of icodextrin on glycemic and lipid profiles in diabetic patients undergoing peritoneal dialysis. Am J Nephrol. 2007;27(4):409-15.

41. Marshall J, Jennings $P$, Scott $A$, Fluck RJ, Mclntyre CW. Glycemic control in diabetic CAPD patients assessed by continuous glucose monitoring system (CGMS). Kidney Int. 2003;64(4):1480-6. 